\title{
A CASE STUDY ON ASSEMBLY LINE BALANCING OF VEHICLE MANUFACTURING UNIT
}

\author{
Syed Afzal Ali ${ }^{1}$, Dr. Ravindra Mohan ${ }^{2}$ \\ PG Scholar ${ }^{1}$, Assistant Professor ${ }^{2}$ \\ Department of Mechanical Engineering, SATI (Engineering College), Vidisha
}

\begin{abstract}
Line balancing means balancing the production line, or any assembly line. The main objective of line balancing is to distribute the task over the each work station so that idle time of labor of machine can be minimized. Line balancing aims at grouping the resources or labor in an efficient and best pattern in order to obtain an optimum or proper balance of the resources and flows of the production or assembly processes. Assembly Line Balancing (ALB) is the term commonly used to refer to the decision process of assigning tasks to workstations in a sequence way to production system. The task of elemental operations required to build raw material in to finished product.

Line Balancing is a classic Operations Research optimization technique which has significant industrial importance in lean system. The concept of mass production essentially involves the Line Balancing in assembly of identical or interchangeable parts or components into the final product in various stages at different workstations. With the improvement in knowledge, the refinement in the application of line balancing procedure is also a must. Task allocation of each worker was achieved by assembly line balancing to increase an assembly efficiency and productivity. In this paper, we discuss and analysis a vehicle manufacturing unit and suggest the options to increases the productivity through assembly line balancing with the help of Pro Balance.
\end{abstract}

Keywords: Assembly Line Balancing, Pro Balance, Lean Production, Productivity

\section{INTRODUCTION}

Line Balancing means balancing the production line, or any assembly line. The main objective of line balancing is to distribute the task over the each work station so that idle time of labour of machine can be minimized. Line balancing aims at grouping the resources or labour in an efficient and best pattern in order to obtain an optimum or proper balance of the resources and flows of the production or assembly processes. Assembly Line Balancing (ALB) is the term commonly used to refer to the decision process of assigning tasks to workstations in a sequence way to production system. The task of elemental operations required to build raw material in to finished product.

A product, according to Askin [2] is "any item that is designed, manufactured and delivered with the intention of making a profit for the producer by enhancing the quality of life of the customer. Most products are made up of various parts, where a part can be described as a single unit of a product that are brought together with others to form the finished product. Assembly, therefore, can be explained as

the operation of bringing parts together, either manually by operators or automatically by robots, to form a finished product. Fixing of more complex parts that have more than one component before being assembled to the work-piece as a single unit is called a sub-assembly. A work-piece is an unfinished product whose assembly is in progress

In order to establish a comprehensive understanding of the dynamics of assembly, it is essential to be familiar with the stages and various elements involved in the assembly process. Figure 1 attempt to provide a brief overview of a typical assembly process by highlighting the major constituents of an assembly line.

\section{Work station}

A (work) station is a segment of the assembly line where a certain amount of the total assembly work is performed. Each station on an assembly line is set up with all the materials, machines, tools, jigs/fixtures, instructions and operators needed for the operation(s) assigned. A work-piece does not return to the station it has already visited at an assembly line. [3] [19]

\section{Operation (task)}

The assembly process of a product consists of a sequenced set of actions that are applied to the work-piece as it moves on the line. Each of these indivisible actions is called an operation.

\section{Operator}

Who performs an operation on an assembly line is an operator. Operators perform their tasks either manually by using hand tools, or semi-manually by using automatic tools or task-specific machines. Minimum number of operators required to complete all tasks on an assembly line is calculated as,

Minimum number of assemblers $=$ Total assembly time of the product/ Target time

However, this is only a theoretical calculation and in most cases, due to some restrictions, this calculation does not give reliable results. For instance,

This calculation gives the minimum number of operators required for the assembly of a specific product. However, total assembly time of different products processed at the same line can differ, which results in different assembler demands.

Organization of the assembly line is an important factor while defining operator demand, i.e., assemblers does other time consuming work than assembly at the line such as material handling, walking, picking etc. 


\section{IJO-SCIENCE}

\section{(INTERNATIONAL JOURNAL ONLINE OF SCIENCE)}

ISSSN: 2455-0108

Therefore, assembly time data only is not enough to evaluate operator demand. [3]

Material handling

Material handling can be explained as the extra work that a part is subjected to from the time it becomes ready for assembly until it is assembled. This work includes transportation, storage and sequencing of parts as well as rework on the parts to be assembled. In an ideal system, a part that is ready for assembly should directly be transported to the site of assembly in order to eliminate the extra cost that will emerge for storage and further transportation. Material handling does not add any value to the finished product and is the greatest source of waste in a production system that should be minimized.

\section{Material flow}

Continuous transportation of raw materials, parts and components from their source locations, i.e., suppliers, warehouses, sub-assembly stations etc, to their assembly locations until they are used in the production system is called material flow. Material flow is a very critical aspect of production since any problem that occurs during this process can affect the whole production system, which may even cause the whole system to stop until the required item is received.

\section{Product process pattern}

Product process pattern defines the production strategy of a facility decided by the producer according to production capacity and product features. The two main product process systems are job shop production system and flow line production system. Scholl ([19] p. 1) defines job shop production systems as job-oriented workshops where machines performing similar operations are combined, and flow line production systems as facilities that are arranged according to the technological sequence of operations.

The product process matrix proposed by Hayes and Wheelwright (1979) describes the dynamic nature of product and process choices and represents the strategic choices available to firms in both product and process dimensions. According to Schroeder ([20] p. 64), "The diagonal of the matrix represents a match between the product and process; a low-volume product with high variety would be produced by a job shop, while a highly standardized product with high volume would be produced by a continuous process. Any firm operating off the diagonal is likely to have either the wrong product or the wrong process to remain competitive." According to Scholl [19], the main advantages of flow line systems relative to job shop production systems are,

- High capacity utilization and small throughput times,

- Low in process inventories,

- Regular and simple material flow,

- Reduced need for material handling due to transferring of work pieces by mechanical handling equipment like conveyor belts,

- Less space need for storage and material movement, which reduces the required shop floor space,

\section{VOLUME II ISSUE IV July 2016}

- Ability to use less skilled operators who can be trained more quickly due to strict division of labor,

On the contrary, he emphasizes the disadvantages of these systems as,

- High capital requirements for the installation of the system,

- Low job satisfaction of workers employed at flow lines due to high degree of labor division, which creates simple and monotonous job contents as well as leading to high absenteeism and turnover rates of workers,

- Inflexibility of systems due to high degree of specialization, which becomes disadvantageous especially with respect to the steady shortening of product life cycles,

- System failure risks due to machinery; maintenance and repairs become critical issues since machine brakedowns may stop the complete system. The same is true if the requisite material is not available.

- System failure risks due to quality; the quality control must directly be included into the production process with the existence of inspection stations. When failures occur the complete line may be affected.

Regarding these aspects; standardized products, high volume production, stable product demands and continuous supply of material is mandatory for successful installation of flow line systems. [19]

\section{Order initiation}

Decision of production is customer-oriented; producers define what and how to produce according to the demand of customers. Producers design production process with three major strategies; Make-to-Stock (MTS), Make-to-Order (MTO) and Assemble-to-Order (ATO).

In the MTS system, producers specify a product range according to customer demands and the finished products are stocked. The strategy behind this system is to stock the products that are assumed to be demanded, and to supply these products immediately on demand. Forecasting, inventory management and capacity planning play very important roles in this process. Although

MTS system can provide fast service with lower costs; product customization is not an issue in this system.

In the MTO system however, products are designed and produced according to customer specifications. In this sense, MTO system provides higher flexibility for product customization, but production costs are higher than the MTS system.

The ATO system is in a way a combination of the MTS and MTO systems. In the ATO process, subassemblies that form the products are Made-to-Stock, and when customer order is received, the product specifications are configured and final product is Made-to -Order. Modularity in product design is therefore critical for this production process to be used. [20]

Time constraints

The following sections describe different time parameters that exist in a production system. 


\section{IJO-SCIENCE}

\section{(INTERNATIONAL JOURNAL ONLINE OF SCIENCE)}

ISSSN: 2455-0108

\section{Operation time}

Operation time is the time required to start and finish an operation at a station. [19] Measurement of operation time studies are either made manually by stop-watch, or digitally by image processing techniques. [19]

\section{Cycle time}

Starting from the moment a work-piece is delivered to a station, the required time for all operations at that station to be completed on that work-piece is called cycle time. Cycle time at a station is a function of the total operation time and number of operators at that station. [19]

\section{Target time}

Depending on the production plan shaped according to customer demands, number of products that will leave a production system on a daily basis is a known data. Target time can simply be defined as the required time that must elapse between two consequent product completions, which is also equal to the time for each work-piece on the line taken from its arrival to the current station until its arrival to the next station. Target time is a function of product volume and available production time. [15]

\section{Target time $=$ Net available production time $/$ Demand}

From the definition, target time is the same for all stations on an assembly line, and it should not be confused with cycle time. Target time is the time for which a work-piece stays at a station; cycle time is the time for which operations are completed while the work-piece is at the station.

\section{Target overdue}

The case when all assigned operations at a station could not be completed within the target time is called target overdue.

\section{Idle time}

Idle time (waiting time) defines the period in which no operations are held at a station after all operations are completed and the work-piece stays idle until being moved to the next station. Since cycle time differs for different stations of a line, idle time is also different for each station. For individual stations it can be expressed as,

\section{Idle time $=$ Target time - Cycle time}

The sum of idle times for all stations of the line is called the balance delay time. [19]

\section{Tolerance time}

The required time for a work-piece to be delivered to the next station after it is processed at the current station is called tolerance time. [19]

\section{Throughput time}

Throughput time is the total time for a work-piece to enter a production line and leave the line as the finished product, which is equal to the total processing and waiting times of that production system. [19]

\section{Labor productivity}

Labor productivity is the amount of output that an operator produces in unit time. This can be formulated as,

$\mathrm{P}_{\mathrm{a}}=\mathrm{F}_{\mathrm{v}} / \mathrm{I}_{\mathrm{a}}$,

\section{VOLUME II ISSUE IV July 2016}

Where $F_{v}$ and $I_{a}$ represents the number of buses that leave the pre-assembly line in a given time and number of operators at the pre-assembly line respectively. [21]

\section{LITERATURE REVIEW}

Lean and agile manufacturing is a very vast field and Line Balancing in industries is also very important. Many times in conferences this is main topic of discussion and many students and scholars also publish their work on this topic. Amen (2000) [1] presented work on an exact method for cost-oriented assembly line balancing. Characterization of the cost oriented assembly line balancing problem had been shown by without loading the stations maximally the costoriented optimum. According to him criterion two stationsrule had to be used. An exact backtracking method was introduced for generating optimal solutions in which the enumeration process was limited by modified and new bounding rules. Results of an experimental investigation showed that the new method finds optimal solutions for small and medium-sized problem instances in acceptable time. A survey on heuristic methods for cost-oriented assembly line balancing was presented by Amen (2000) [2]. In this work main focus was on cost-oriented assembly line balancing. This problem mainly occurs in the final assembly of automotives, consumer durables or personal computers, where production is still very labor-intensive, and where the wage rates depend on the requirements and qualifications to fulfill the work. In this work a short problem description was presented along with classification of existent and new heuristic methods for solving this problem. A new priority rule called best change of idle cost was proposed. This priority rule differs from the existent priority rules because it was the only one which considers that production cost were the result of both, production time and cost rates. A work on new heuristic method for mixed model assembly line balancing problem was published by Jin and Wu (2002) [3]. A goal chasing method was presented which is a popular algorithm in JIT system for the mixed model assembly line balancing problem. In this work, definition of good parts and good remaining sequence were provided and analyze their relationship with the optimal solutions objective function value. A new heuristic algorithm was also developing called variance algorithm' the numerical experiments showed that the new algorithm can yield better solution with little more computation overhead

Fleszar and Hindi (2003) [4] presented a work on enumerative heuristic and reduction methods for the assembly line balancing problem. They presented a new heuristic algorithm and new reduction techniques for the type 1 assembly line balancing problem. The new heuristic was based on the Hoffmann heuristic and builds solutions from both sides of the precedence network to choose the best. The reduction techniques aimed at augmenting precedence, conjoining tasks and increasing operation times. A test was carried out on a well-known benchmark set of problem instances; testify to the efficacy of the combined algorithm, 


\section{IJO-SCIENCE}

\section{(INTERNATIONAL JOURNAL ONLINE OF SCIENCE)}

ISSSN: 2455-0108

in terms of both solution quality and optimality verification, as well as to its computational efficiency. A work on assembly line balancing in a mixed model sequencing environment with synchronous transfers was presented by Karabati and Sayin (2003) [5].

An assembly line balancing problem was considered in a mixed-model line which was operated under a cyclic sequencing approach. Study of the problem was done in an assembly line environment with synchronous transfer of parts between the stations.

They formulated the assembly line balancing problem with the objective of minimizing total cycle time by incorporating the cyclic sequencing information. They showed that the solution of a mathematical model that combines multiple models into a single one by adding up operation times constitutes a lower bound for this formulation. An alternative formulation was proposed that suggested minimizing the maximum sub cycle time.

A work was presented by Simaria and Vilarinho (2004) [6] on genetic algorithm based approach to the mixed-model assembly line balancing problem of type II.

According to them mixed-model assembly lines allow for the simultaneous assembly of a set of similar models of a product. A mathematical programming model was presented in this work and an iterative genetic algorithm based procedure for the mixed-model assembly line balancing problem with parallel workstations, in which the goal was to maximize the production rate of the line for a predetermined number of operators.

A fuzzy logic approach to assembly line balancing work was presented by Fonseca et al. (2005) [7]. This work deals with the use of fuzzy set theory as a viable alternative method for modeling and solving the stochastic assembly line balancing problem. Variability and uncertainty in the assembly line balancing problem had traditionally been modeled through the use of statistical distributions. Fuzzy set theory allowed for the consideration of the ambiguity involved in assigning processing and cycle times and the uncertainty contained within such time variables. COMSOAL and Ran-ked Positional Weighting Technique were modified to solve the balancing problem with a fuzzy representation of the time variables. The work showed that the new fuzzy methods capabilities of producing solutions similar to, and in some cases better than, those reached by the traditional methods. Gokcen (2005) [8] presented a work on shortest route formulation of simple U-type assembly line balancing problem. A shortest route formulation of simple U-type assembly line balancing (SULB) problem was presented. This model was based on the shortest route model developed in for the traditional single model assembly line balancing problem. Agpak and Gokcen (2005) [9] presented their work on assembly line balancing: Two resource constrained cases. A new approach on traditional assembly line balancing problem was presented. The proposed approach was to establish balance of the assembly line with minimum number of station and resources and for this purpose, 0-1 integer-

\section{VOLUME II ISSUE IV July 2016}

programming models were developed.

A work was presented by Bukchin and Rabinowitch (2006) [10] on branch and bound based solution approach for the mixed-model assembly line balancing problem for minimizing stations and task duplication costs. A common assumption in the literature on mixed model assembly line balancing is that a task that is common to multiple models must be assigned to a single station. In this work a common task to be assigned to different stations for different models. The sum of costs of the stations and the task duplication was to be minimized. An optimal solution procedure based on a backtracking branch and bound algorithm was developed and evaluates its performance via a large set of experiments. For solving large-scale problems branch and bound based heuristic was developed.

Levitin et al. (2006) [11] works on genetic algorithm for robotic assembly line balancing. Flexibility and automation in assembly lines can be achieved by the use of robots. The robotic assembly line balancing

(RALB) problem was defined for robotic assembly line, where different robots may be assigned to the assembly tasks, and each robot needs different assembly times to perform a given task, because of its capabilities and specialization. The solution to the RALB problem includes an attempt for optimal assignment of robots to line stations and a balanced distribution of work between different stations. It aims at maximizing the production rate of the line. Gokcen and Agpak (2006) [12] presented their work on goal programming approach to simple U-line balancing problem. A goal programming model for the simple U-line balancing (ULB) problem was developed. The proposed model which was the multi criteria decision making approach to the U-line version provides increased flexibility to the decision maker since several conflicting goals can be simultaneously considered.

A work on heuristic solution for fuzzy mixed model line balancing problem was presented by Hop (2006) [13]. This work addresses the mixed-model line balancing problem with fuzzy processing time. A fuzzy binary linear programming model was formulated for the problem. This fuzzy model was then transformed to a mixed zero one program. Due to the complexity nature in handling fuzzy computation, new approximated fuzzy arithmetic operation was presented. A fuzzy heuristic was developed to solve this problem based on the aggregating fuzzy numbers and combined precedence constraints. The general idea of our approach was to arrange the jobs in a sequence by a varying-section exchange procedure. Then jobs were allocated into workstations based on these aggregated fuzzy times with the considerations of technological constraint and cycle time limit. Promising results were obtained by experiments.

Gamberini et al. (2006) [14] presented their work on a new multi-objective heuristic algorithm for solving the stochastic assembly line re-balancing problem. In this work a new heuristic for solving the assembly line rebalancing problem was presented. The method was based on the integration of a 


\section{IJO-SCIENCE}

\section{(INTERNATIONAL JOURNAL ONLINE OF SCIENCE)}

ISSSN: 2455-0108

multi-attribute decision making procedure, named technique for order preference by similarity to ideal solution (TOPSIS), and the well known Kottas and Lau heuristic approach. The proposed methodology was focused on rebalancing an existing line, when some changes in the input parameters (i.e. product characteristics and cycle time) occur. Hence, the algorithm deals with the assembly line balancing problem by considering the minimization of two performance criteria: (i) the unit labor and expected unit incompletion costs, \& (ii) tasks reassignment. A work was presented by Song (2006) [15] on recursive operator allocation approach for assembly line-balancing optimization problem with the consideration of operator efficiency. An optimization model was used for assembly line balancing problem in order to improve the line balance of a production line under a human centric and dynamic apparel assembly process. An approach was proposed to balance production line through optimal operator allocation with the consideration of operator efficiency. Two recursive algorithms were developed to generate all feasible solutions for operator allocation. Three objectives i.e. the lowest standard deviation of operation efficiency, the highest production line efficiency and the least total operation efficiency waste were rearranged to find out the optimal solution of operator allocation. The performance comparison demonstrated that the proposed optimization method outperforms the industry practice.

Dolgui et al. (2006) [16] works on special case of transfer lines balancing by graph approach. In their work for paced production they considered a balancing problem lines with workstations in series and blocks of parallel operations at the workstations. Operations of each workstation were partitioned into blocks. All operations of the same block were performed simultaneously by one spindle head. All blocks of the same workstation were also executed simultaneously.

The operation time of the workstation was the maximal value among operation times of its blocks. The line cycle time was the maximal workstation time. A method for solving the problem was based on its transformation to a constrained shortest path problem.

A survey on problems and methods in generalized assembly line balancing was presented by Becker and Scholl (2006) [17]. Assembly lines are traditional and still attractive means of mass and large scale series production. Since the early times of Henry Ford several developments took place which changed assembly lines from strictly paced and straight single model lines to more flexible systems including, among others, lines with parallel work stations or tasks, customer oriented mixed model and multi-model lines, U-shaped lines as well as un paced lines with intermediate buffers. Assembly line balancing research had traditionally focused on the simple assembly line balancing problem which had some restricting assumptions. Recently, a lot of research work had been done in order to describe and solve more realistic generalized problems. Kim et al. (2006) [18] presented his work on endo symbiotic evolutionary algorithm

\section{VOLUME II ISSUE IV July 2016}

for the integration of balancing and sequencing in mixedmodel U-lines. A new evolutionary approach in mixed model U-shaped lines was proposed to deal with both balancing and sequencing problems. The use of U-shaped lines was an important element in Just-In-Time production. For an efficient operation of the lines, it is important to have a proper line balancing and model sequencing. A new genetic approach was proposed to solve the two problems of line balancing and model sequencing called endo symbiotic evolutionary algorithm.

Peeters and Degraeve (2006) [21] works on linear programming based lower bound for the simple assembly line balancing problem. The simple assembly line balancing problem was a classical integer programming problem in operations research. A set of tasks, each one being an indivisible amount of work requiring a number of time units, must be assigned to workstations without exceeding the cycle time. They presented a new lower bound, namely the LP relaxation of an integer programming formulation based on Dantzig-Wolfe decomposition. A column generation algorithm was proposed to solve the formulation and a branch-and-bound algorithm also proposed to exactly solve the pricing problem.

A work on optimal piecewise-linear program for the U-line balancing problem with stochastic task times was published by Urban and Chiang (2006) [22]. The utilization of Ushaped layouts in place of the traditional straight-line configuration has become increasingly popular. This work examines the U-line balancing problem with stochastic task times. A chance constrained, piecewise linear, integer program was formulated to find the optimal solution. Various approaches were used to identify a tight lower bound.

Computational results showed that the proposed method was able to solve practical sized problems.

Hirotani et al. (2006) [23] works on analysis and design of self-balancing production line. In a self balancing production line each worker was assigned work dynamically. In this work, they examine other less restrictive conditions that can achieve the same self balancing effect, and furthermore, characteristics of this line were analyzed by deriving the imbalance condition and analyzing the influence of initial position. In addition, a method for designing a self-balancing line based on our results was proposed. A work was presented by Dimitriadis (2006) [22] on assembly line balancing and group working: A heuristic procedure for workers groups operating on the same product and workstation. In this work they examined an assembly line balancing problem that differs from the conventional one in the sense that there were multi-manned workstations, where workers groups simultaneously perform different assembly works on the same product and workstation. The proposed approach here results in shorter physical line length and production space utilization improvement, because the same number of workers can be allocated to fewer workstations. A heuristic assembly line balancing procedure was thus developed and illustrated. Finally, experimental results of a 


\section{IJO-SCIENCE}

\section{(INTERNATIONAL JOURNAL ONLINE OF SCIENCE)}

ISSSN: 2455-0108

real-life automobile assembly plant case and well known problems from the literature indicate the effectiveness and applicability of the proposed approach in practice.

III. METHODOLOGY AND PROCEDURE

Precedence information of operations is the most important data while sequencing and distributing operations among stations. Precedence indicates the order and priority relationship between operations in the same process. In order to determine the most efficient sequence of operations at the line, i.e., by minimizing the risk of dismantling of a part for assembly of another part or rework, correct formation of the precedence relation of operations is very critical.

Operations are classified as series and parallel, implying that series operations must be done one after the other and parallel operations can be done at the same time without interfering each other. After the precedence relation is determined, distribution of operations to stations and to operators at stations is held according to the order and classification of operations. Figure 2.9 features an example precedence diagram of 10 operations. Operation $2-1$ is the predecessor of all the following operations; after 2_1, 2_2 and 2_5 can start in parallel. 2_2, 2_3 and 2_4 are series operations. Operation 4_4 can only be made after 4_1, 4_2 and $4 \_3$ are completed.

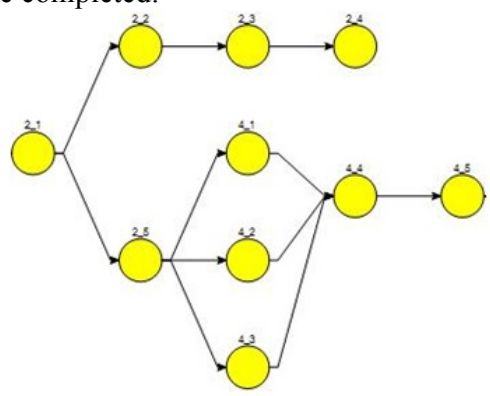

Figure 1: Cluster Design

There are some key issues for assigning operations to operators at the assembly line. The first and most critical limitation about performance of operators making manual assembly is explained by Ortiz [15] as $85 \%$ rule, which simply suggests cycle time at a station not to exceed $85 \%$ of the target time. According to Ortiz [15], "Operators cannot work at optimum rate or speed, $100 \%$ of their shift, or they will become less productive, create more defects, become injured, and miss more days on the job. A realistic operator load of $85 \%$ allows for a smooth and efficient flow of product, without jeopardizing quality, productivity, or health. The $85 \%$ loading is not slow; it simply allows operators to work at a productive rate, which results in properly built, quality products."

In order to minimize non-value added work during assembly such as walking, sequencing etc.,

Supplied materials should be ready to assemble and positioned at arm's reach or behind the operator which can be reached by simply turning behind

\section{VOLUME II ISSUE IV July 2016}

Working environment should allow the operator to use both hands during operations

And work instructions should be clearly stated; assemblers should not spend time thinking about how to make the assembly. [15]

Different target times require different job designs in terms of operator performance. [3] explains this as "For instance, at very short target times the work is too repetitive which threats human endurance and causes repetitive stress injuries, while at very long target times it is not repetitive enough for the assembler to fall into a routine that he or she can follow without having to think about it.". Operators run the risk of forgetting where they are and skipping a step by mistake. Therefore, while assigning tasks, physical and mental capacity of operators should be considered as well as the ergonomic requirements of the tasks.

Schroeder [18] defines bottleneck as, "a work center whose capacity is less than the demand placed on it and less than the capacities of all other resources. A bottleneck resource will constrain the capacity of the entire shop and an hour added to the bottleneck will add an hour of capacity to the entire factory. An hour added to the non-bottleneck work center will not help the schedule at all since the excess capacity exists there."

Not assigned to a specific operation or a station, a joker worker functions to meet the on-demand extra labor or operator replacement requirement at any station of the assembly line. This need may arise if a complex model with heavy assembly work is at a station and there is a risk of target overdue, or if an operator is absent at a station. Joker workers can be involved in various works at the facility such as Kaizen activities, maintenance, sub-assembly stations etc. when they are not required at the assembly line.

The term "sustainability" has been spelled for the first time in 1974 in the World Council of Churches and highlights the importance of maintaining the living and non-living resources of our planet. In 1987, Gro Harlem Brundtland, who was the Norwegian Prime Minister and the UN World Commission on Environment and Development Chair of the time, published the report "Our Common Future", where the idea of sustainable development has been introduced for the first time. This idea can be basically summarized as "the development that meets the needs of the present without compromising the ability of future generations to meet their own needs".

The objectives of this project, which are to restructure and balance an existing assembly line, requires a set of compulsory procedures to be followed in order to achieve reliable results. First of all, it is crucial to have a complete list of operations of the assembly line and their times, because this data is the basic reason for a line to exist, and evaluation of the balance of a line cannot be made without this data. As the next step, it is important to evaluate the balance losses of the existing line for determination of factors that cause these losses. Finally, after eliminating these factors, the assembly line is structured according to desired 


\section{IJO-SCIENCE}

\section{(INTERNATIONAL JOURNAL ONLINE OF SCIENCE)}

ISSSN: 2455-0108

specifications.

This first section of this chapter introduces the stages of the project and highlights the steps taken at each stage. In the second section, the applied methodology to carry out this study is portrayed in a detailed structure.

The tool that is used for maintaining the optimum balance on the production line is Pro Planner ${ }^{\circledR}$ Line Balance (Pro Balance 3.0.0.0) software. The software calculates the best balance with respect to the input data, which can then be manually manipulated for further modifications. It is possible 3 . to modify all input data in a matter of seconds, making visualization of different options and their results in a short time, and bringing in a great flexibility for the evaluation process. The quality of results generated by the software is strongly related to the quality of the input data; the more details are provided, the better solutions are received.

The data input to Pro Balance for this work includes;

- $\quad$ Production type (mixed model),

- Operation names and times,

- Time unit (minutes),

- Work zones of operations,

- Product model (important for mixed model balancing),

- Resources required for the corresponding operations,

- Number of stations,

- Number of operators at each station,

- Monumental resources at stations,

- Desired target time,

- Precedence of operations.

\section{IMPLEMENTATIONS}

In order to balance an assembly line, it is mandatory to have 8 . knowledge of all assemblies that are made on the line of interest, their sequence and precedence relation and the operation times.

At the assembly line that is to be analyzed, the assembly of 16 different bus types and their variants is handled. Even 9. though similar processes are applied to all vehicle types, there are some processes of different operation times for different vehicles, or some type-specific processes for vehicles. Therefore it is of great importance to clarify and consider these differences while maintaining the line balance. The method applied to perform the balancing study at the bus pre-assembly line is stated below.

1. Total number of stations at the line is determined.

2. The operations applied at these stations are crosschecked with the process lists of the Work Preparation Group and a complete process list of the pre-assembly line is prepared. This is done in two steps.

- The existing process list of the assembly line is divided according to their distribution to stations. These lists are printed out and taken to the corresponding stations. The processes applied at the stations are both visually observed and also checked by interviews with the operators at the

\section{VOLUME II ISSUE IV July 2016}

stations so that the missing / misaddressed / readdressed operations are determined and updated on the list.

Factory database is used to enlist all materials that are addressed to the pre-assembly stations for assembly. This database shows which item is addressed to which station in the factory for all vehicle models. This list is used to check the assemblies at the pre-assembly stations through the items that are addressed to these stations for assembly.

This updated list shows all processes that are applied at the pre-assembly stations. However, there are operations that differ for different vehicle models and also some similar operations are completed in different durations for different models (i.e., task time of electrical systems assembly of city buses is nearly half of that of coaches). Therefore a complete process list for all three vehicle types of interest is prepared by using the updated process list.

4. Operation times and number of operators for all processes of each of the three vehicle types are calculated. This is done by checking the existing operation time list and making time studies for missing operations. Analysis of the balance losses at the current line is made with this information.

5. For the next step of the work, which is to reorganize the production line and balance the operations at the stations, further studies are made and added to the existing data, which is to be used for running ProBalance ${ }^{\circledR}$.

6. In order to achieve a leaner assembly line, sources of wastes at the production process are determined.

7. Operations at the stations are analyzed and improvement options such as removal of stations, merging stations or cancelling processes by improving prior operations etc. are evaluated.

In order to maintain a standard expression of vehicle regions, a coding scheme is prepared. The primary objective of coding is to prevent assignment of two operations to the same region at the same time in order to provide sufficient workspace for operators during assemblies.

Clusters are created in ProBalance ${ }^{\circledR}$ for related tasks and these clusters are sequenced according to their precedence relationship. The purpose of this is to collect similar tasks under the same clusters and making mapping the precedence of operations easier since total number of tasks reaches a few hundreds.

10. A data sheet template for collecting the required data to run ProBalance ${ }^{\circledR}$ is prepared.

11. In order to collect the required data for running ProBalance $($, a weekend workshop is planned and arranged with the attendance of production engineers and 10 operator team leaders of the pre-assembly line, and Work Preparation Group. After Workshop 1;

12. According to the data collected, task lists for the 3 primary vehicle models are prepared,

13. Tasks are divided such that, if a task of 85 minutes/operator is done by 4 operators, that task is modified on the list as 4 different tasks of 25 minutes. This change is mandatory for the balancing work. 


\section{IJO-SCIENCE}

\section{(INTERNATIONAL JOURNAL ONLINE OF SCIENCE)}

ISSSN: 2455-0108

14. Considering the accepted change propositions for the line, task lists are finalized.

15. All collected data is sorted on Microsoft Excel and input to ProBalance ${ }^{\circledR}$.

16. Precedence diagrams for the 3 primary models are prepared by following to the procedure stated previously.

17. Balance algorithm is run for 3 bus models individually, but by applying the same station constraints. That is, same equipment is assigned to the same stations for all models so that similar operations are kept at the same stations for all models.

18. Demanded operation distribution to stations is made by manual manipulation on ProBalance $\AA$.

19. In order to prevent the balance losses caused by fixed number of operators at stations, joker workers are assigned.

20. Planning of operators at the bus pre-assembly line is done by calculating the number of operators that is fixed for each station. This is done by using the balancing results of the 3 vehicle models. For three models, number of operators at each of the 22 stations is calculated. For each station, demand for the least number of operators is taken as the base operator number for that station. For instance, for station D01; A21, P22 and R13 models require 10, 9 and 13 operators respectively. Thus, since the least number of demanded operators is 9 among the 3 models, fixed number of operators at station D01 is calculated as 9. When another model is at the station, the extra work force is provided by the joker workers. The same method is applied while calculating the fixed number of operators for all 22 stations. These calculations are shown in more detail in next chapter.

21. Considering the new number of stations, the factory space available and other constraints, a layout proposal is prepared.

22. Comparison and evaluation of the current state and the new state of the bus pre-assembly line is made.

\section{RESULTS}

Production in the factory is performed on a mixed-model flow-line system. The whole assembly system consists of 136 serial workstations, 38 of which are two parallel lines of 19 stations. Bus production line is controlled by 5 main departments in three buildings in the factory. They are;

- Bus Chassis Assembly

- Paint shop

- Bus Pre-Assembly

- Bus Assembly

- Bus Finish

Each department is responsible from the segment of the production line where the processes under their control are held and each of these sections is regarded as independent lines. That is, there are 5 consequent lines in the factory that make up the bus production line. Chassis assembly, paint shop and bus pre-assembly lines are located in building U1, and bus assembly and bus finish lines are located in U2 and U3 respectively. All lines except the bus pre-assembly line are single assembly lines. Bus pre-assembly line functions with two parallel lines D and E. Working process inventory

\section{VOLUME II ISSUE IV July 2016}

of the whole bus assembly line - including buffers- is 225 units, however, current number is 287 because of the pauses in production due to the global economic situation. This difference is caused by the increased number of vehicles waiting at the buffers. Among the 5 lines, bus pre-assembly line has the highest working process inventory with 38 buses. Production is low-volume with about 2000 units per year. There is no automation throughout the production process. Conveyance between stations is unpowered. All tasks including moving the vehicles to the next stations- are performed by human operators.

Product variance is high. There is no limitation for distribution of products and their variants to lines; assembly of each bus model can be handled in both lines. City buses, intercity buses and coaches of MAN and NEOPLAN brands, making 16 different bus models, are produced on the same line. Every single vehicle is configured individually due to customer requests, which increases the complexity of the assembly process. Task times vary for different bus models, i.e., roof wiring for A21 takes 180 minutes /operator while it takes 60 minutes/operator for P22.

However, in the current setting, number of workers is fixed for stations. While planning production, total task times of vehicles are considered, i.e., two complex models is not planned consecutively on the same line.

There are no joker workers. Division of labor among operators is high, which makes replacement for absent operators problematic.

Material flow within the factory is managed with the KANBAN system. Produced and outsourced parts are collected in the warehouses and distributed to the stations by the internal logistics unit just-in-time. No outsourced parts are directly delivered to the assembly location. The main problem with the logistics is the missing parts, which results in the operator to leave his/her station, walk to the warehouse and take the part himself/herself. Frequently, this causes target overdue, causing the operator to leave his station and complete his/her work in the next station. For circumstances when the missing part is not in the warehouse, in order not to stop production, the assembly continues with that part missing, causing a rework after it is received.

Manual material handling needs are high, having a dramatic effect on the efficiency of assembly process, i.e., before assembling the glasses, two operators take out the randomly packed glasses from the commissioning trolleys of the supplier onto the glass holding tables, after that they need to sort these glasses in the order of assembly because glasses need to be assembled in a pre-defined order, and only then they can take them and assemble.

Production process is built on assemble-to-order system; every bus is taken to the line after they are configured individually by their customers and the payment is made. Production capacity of the factory is planned for 8 vehicles per day. Daily working time is 520 minutes. Target time is 65 minutes and throughput time is 15600 minutes for the whole line. Buffers are the primary reason for this long throughput 


\section{IJO-SCIENCE}

\section{(INTERNATIONAL JOURNAL ONLINE OF SCIENCE)}

ISSSN: 2455-0108

time. In the two line bus pre-assembly line only, this target time is applied as 130 minutes. The line delivers two vehicles in 130 minutes, one of which is directly delivered to the bus assembly line of target 65 minutes while the other vehicle is taken to the parking area for waiting. In the next target, while the operations in the pre-assembly line continue, this waiting vehicle is delivered to the assembly line. Throughput time for the bus pre-assembly line is 2470 minutes.

The reason for the bus pre-assembly line to operate as two parallel lines is the time requirement for operations that take longer time than the target time. These processes are mainly indivisible, i.e., waiting for adhesives or isolation tools to dry, and due to the precedence relations of the operations, it is not possible to start the following process while the previous is in progress, i.e., wiring cannot begin before piping is completed since both systems are installed to the same sections of the vehicle that do not allow two operators work together.

Although the production system is flow line, the advantages of flow line production systems pointed out by Scholl [17] are not valid for the bus pre-assembly line; throughput times are high, in-process inventory is high, material handling requirements are high due to unpowered conveyance and it is not possible to train unskilled operators quickly for the tasks held at the main line. Also, the production system is off the diagonal of the product-process matrix of Hayes and Wheelwright (1979) with its low volume production.

\section{CONCLUSION}

\section{Labor productivity}

The number of assembled vehicles at the pre-assembly line is not subject to change throughout this study. Therefore, due to the reduced number of operators at the pre-assembly line, the labor productivity will increase with the application of the proposed system. The rate of increase mainly depends on which scenario is to be applied and an improvement of up to $20 \%$ in labor productivity is possible in the future system.

\section{Efficiency}

One of the most important objectives of this project was to eliminate the excess capacity at the stations so that idle times and non-value-added work at the production system are minimized. Considering that the same number of output is produced by a smaller number of operators in the same duration, and the process times are reduced for the same products, it can be said that the efficiency of the preassembly line increased as a result of this study. Besides, reduced idle times at stations and new strategies developed for handling operations that cause target overdue -which is the greatest waste in terms of efficiency- are other factors that improve the efficiency of the line. Different from the previous system, operations causing target overdue will not be completed by rework. Instead, they will be completed by joker workers instantly at the corresponding station so that wastes caused by over-processing will be eliminated. With the new line balance and operator planning, the maximum balance delay time (total idle time) at the line can be reduced

\section{VOLUME II ISSUE IV July 2016}

up to $80 \%$. Also, the maximum total target overdue can be reduced $90 \%$ with the same method.

Layout

The layout of the new pre-assembly line is planned in a way that will preserve the station setup of the previous preassembly line in order to reduce reorganization cost. It was also considered to minimize the distance between the main assembly and sub-assembly stations at the production site. Therefore, the key notion of layout planning was generating the largest possible area for sub-assembly stations as close to the main assembly stations as possible without increasing station setup costs.

Unlike the current layout where most stations were positioned outside the U-shaped pre-assembly line, the new plan suggests sub-assembly stations to be located right in the middle of the U-shaped assembly line, reducing the distance between them and their main assembly stations dramatically and improving material flow.

\section{Reorganization cost}

Proposing solutions that will minimize the reorganization cost has been the primary objective of this study, which had the greatest effect on layout and station planning. Considering the factors that increase reorganization cost, i.e., removing and re-installing large station equipment such as cabins or platforms, digging ground canals, setting up pneumatic systems, etc., and short transition time, the strategy of keeping these equipment at their current positions is applied. Besides, it is tried to be avoided to define new locations as stations that were not stations before, since it would require infrastructural investment to convert those areas to assembly stations.

\section{Material handling}

At the core of this study laid elimination of non-value-added operations at stations that are caused by high material handling requirements of operations, which is the greatest waste in the current production system. Although bus production requires manual assembly up to a large extent, this does not necessarily mean that operators are obliged to do additional labor at the assembly stations such as unpacking, or making adjustments on the parts to be assembled. In order to get rid of these operations and create an assembly line where operators perform "grab and assemble" operations only, it was an important part of the project to determine the tasks that could be removed from the pre-assembly stations to sub-assembly stations. In addition, logistics department is briefed on issues regarding how parts are supposed to be supplied to the stations for minimizing handling losses. 95\% of the reduced operation time for vehicles is a result of re-addressing of required operations to sub-assemblies and elimination of material handling requirements at stations caused by inappropriately supplied parts.

\section{Material flow}

The new layout provides significant improvement on material flow to pre-assembly stations. Unlike the current line, where 


\section{IJO-SCIENCE}

\section{(INTERNATIONAL JOURNAL ONLINE OF SCIENCE)}

ISSSN: 2455-0108

the short distance between parallel lines makes it difficult for fork-lifts to enter, the new line overcomes that problem with large free area around the stations. In addition, the distances between the new pre-assembly stations and the associated sub-assembly stations are much shorter than they are in the current system, which reduces wastes caused by transportation and walking.

\section{Process times}

The improvements on the current production system focused on eliminating noticeable wastes in and removing operations that are not appropriate for the pre-assembly line. By planning the required changes for readdressing those operations and removing them from the pre-assembly line, a substantial reduction of line operation time of about $29 \%$ is achieved.

\section{Joker worker organization and compatibility}

For the assembly system of interest at which product variance is very high, using joker workers will provide the best solution for optimizing line capacity and eliminating variance losses. Considering the minimum and maximum operator requirements at the stations, a joker worker organization of maximum 29 operators would fulfill the requirements of the assemblies on the line for the whole product range.

29 operators, however, is considerably a great number for a line of 160 operators. Planning the schedule of the joker workers is an important task since the cost of an idle joker worker is no different from an idle assembly operator. Therefore, joker worker schedules should be planned parallel to production so that there will be no problems with the line flow due to additional labor demands. When the joker workers are not assigned to any operations at stations, they can take part in Kaizen activities as well as doing rework.

Although the concept of using joker workers at the preassembly line is new, such organization would be compatible with the structure of the company since continuous improvement philosophy is a part of the company culture and is managed by an independent department, which can organize and direct the joker worker activities together with the production management.

\section{REFERENCES}

[1] Amen (2000)"An exact method for cost oriented assembly line balancing". International Journal of Production Economics, Vol. 64, pp. 187-195.

[2] Matthias Amen Int. (2000) "Heuristic methods for cost-oriented assembly line balancing: A survey". International Journal of Production Economics, Vol. 68, pp. 1-14.

[3] Mingzhou Jina, S. David Wub (2002) "A new heuristic method for mixed model assembly line balancing problem". Computers \& Industrial Engineering, Vol. 44, pp.159-169.

[4] Krzysztof Fleszar, Khalil S. Hindi (2003) "An enumerative heuristic and reduction methods for the assembly line balancing problem". European Journal of Operational Research Vol. 145, pp. 606-620.

[5] Selcuk Karabati, Serpil Sayin (2003) "Assembly line balancing in a mixed-model sequencing environment with synchronous transfers". European Journal of Operational Research, Vol. 149, pp.417-429.

\section{VOLUME II ISSUE IV July 2016}

[6] Ana Sofia Simaria, Pedro M. Vilarinho (2004) "A genetic algorithm based approach to the mixed model assembly line balancing problem of type II". Computers \& Industrial Engineering, Vol. 47, 391-407.

[7] D.J. Fonseca, C.L. Guest, M. Elam, and C.L. Karr (2005) "A Fuzzy Logic Approach to Assembly Line Balancing". Mathware \& Soft Computing, Vol.12, pp. 57-74.

[8] Hadi Gokcen, Kursat Agpak, Cevriye Gencer, Emel Kizilkaya (2005) "A shortest route formulation of simple U-type assembly line balancing problem" Applied Mathematical Modelling Vol.29, pp. 373-380.

[9] Kursad Agpak, Hadi Gokcen (2005) "Assembly line balancing: Two resource constrained cases". Int. J. Production Economics Vol.96, pp.129-140.

[10] Adams, W.M. (2006). The Future of Sustainability: Re-thinking Environment and Development in the Twenty-first Century. Report of the IUCN Renowned Thinkers Meeting, 29- 31 January, 2006. Retrieved on: 2009-02-16

[11] Askin, R. G., Goldberg, J. B. (2002) Design and Analysis of Lean Production Systems. John Wiley \& Sons, Inc., New York, ISBN 0-471-11593-2

[12] Baudin, M. (2002) Lean Assembly: The Nuts and Bolts of Making Assembly Operations Flow. Productivity Press, New York, ISBN 1-56327-263-6

[13] Boothroyd, G., Dewhurst, P., Knight, W. (1994) Product Design for Manufacture and Assembly. Marcel Dekker, Inc., New York, ISBN 0-8247-9176-2

[14] Bunting, S. (2005) The Interviewer's Handbook: Successful Interviewing Techniques for the Workplace. Kogan Page Limited, London, ISBN 9780749442934

[15] Cleveland, G., Schroeder, R.G., Anderson, J.C. (1989) A Theory of Production Competence. Decision Sciences 20 (4), 655-668.

[16] Dresner, S. (2002) The principles of Sustainability. Earthscan Publications Limited, London, ISBN: 978-1-84407-706-9

[17] Glassey, W. C. (1966) The Theory and Practice of Time Study. Cox \& Wyman Limited, London

[18] IVF Industrial Research and Development Corporation (2004) Lean Production Presentation as part of the MG2205 Operations Management Course, Royal Institute of Technology, Stockholm

[19] Kolisch, R. (2001) Make-to-Order Assembly Management. Springer- Verlag, Berlin, ISBN 3-540-41098-8

[20] Lung, Y., Chanaron, J. J., Fujimoto, T., Raff, D. (1999) Coping with Variety: Flexible Poductive Systems for Product Variety in the Auto Industry. Ashgate Publishing Company, Vermont, ISBN 0-7546-1115-9

[21] McGilvray, D. (2008) Executing Data Quality Projects: Ten Steps to Quality Data and Trusted Information. Morgan Kaufmann Publishers, San Francisco, ISBN 0-1237-4369-9

[22] Muther, R., Wheeler, J. D. (1994) Simplified Systematic Layout Planning. 3rd Edition, Management and Industrial Research Publications, Georgia, ISBN 0-9336-8409-6

[23] Occupational Safety and Health Organization (2002) Materials Handling and Storing. U.S. Department of Labor, 2236, Washington

[24] Ortiz, C. A. (2006) Kaizen Assembly: Designing, Constructing and Managing a Lean Assembly Line. Taylor and Francis Group, Boca Raton, ISBN 0-8493-7187-2

[25] Porritt, J. (2006). Capitalism as if the world mattered. Earthscan Publications Limited, London, ISBN 9781844071937 


\section{IJO-SCIENCE}

\section{(INTERNATIONAL JOURNAL ONLINE OF SCIENCE)}

ISSSN: 2455-0108

[26] Render, B., Heizer, J. (1997) Principles of Operations Management with Tutorials. 2nd Edition. Prentice-Hall, Inc. New Jersey, ISBN 0-13-840430-5

[27] Sawik, T. (1999) Production Planning and Scheduling in Flexible Assembly Systems. Springer-Verlag, Berlin, ISBN 3540-64998-0

[28] Scholl, A. (1999) Balancing and Sequencing of Assembly Lines. 2nd Edition, Physica-Verlag, Heidelberg, ISBN 3-79081180-7

[29] Schroeder, R. G. (2007) Operations Management: Contemporary Concepts and Cases. 3rd Edition, Mc Graw Hill/Irwin, Singapore, ISBN 007-125436-6

[30] Slack, N., Chambers, S., Jonhston, R. (2007) Operations Management. 5th Edition, Pearson Education Limited, Essex, ISBN 978-0-273-70847-6

\section{VOLUME II ISSUE IV July 2016}

[31] Sule, D. R. (1994) Manufacturing Facilities: Location, Planning and Design. PWS Publishing Company, Boston, ISBN 0-53493435-8

[32] Suri, R. (1998) Quick Response Manufacturing: A Companywide Approach to Reducing Lead Times. Productivity Press, Portland, ISBN 1-56327-201-6

[33] Wagner, B., Enzler, S. (2006) Material Flow Management: Improving Cost Efficiency and Environmental Performance. Physica-Verlag, Heidelberg, ISBN 3-7908-1591-8

[34] Womack, J. P., Jones, D. T. (2003) Lean Thinking: Banish Waste and Create Wealth in Your Corporation. Simon \& Schuster UK Ltd, London, ISBN 0-7432-3164-3 